Open Access

\title{
Assessment of sulphonamides and tetracyclines antibiotic residue contaminants in rural and peri urban dairy value chains in Kenya
}

Joy Deborah Orwa ${ }^{1 *}$, Joseph Wafula Matofari ${ }^{1}$, Patrick Simiyu Muliro ${ }^{1}$ and Peter Lamuka ${ }^{2}$

\begin{abstract}
Background: Antibiotic residues are drug substances found in food from plants or animals initially exposed to antibiotics. In animal husbandry antibiotics have widely been used for the treatment of animal diseases. These residues have the ability to expose the public to serious health hazards. In Kenya drug residues have not only been related to lack of withdrawal periods but also to intentional addition to extend milk's shelf life.

Results: The aim of this study was to investigate the occurrence of 13 veterinary drugs of tetracyclines and sulphonamides along the dairy sub value chain. The study was carried out in Nakuru County which is the leading milk producer in the country. A total of 229 samples were analysed from rural and 80 samples from peri-urban. These were collected from different nodes of the value chain; the farm, milk transporters and at the bulking centers between January 2014 and November 2015. Screening of samples was done by Charm II Blue -Yellow-test while confirmation was done by HPLC-UV for sulfachloropyradizine (SCL), sulfadiazine (SDZ), sulfadimidine (SMTZ), sulfaquinoxaline (SQ), sulfamerazine (SMR), sulfathiazole (STZ), sulfamethoxazole (SMX), sulfadoxin (SDOX), sulfadimethoxin (SDM), oxytetracycline (OTC), doxycycline hyclate (DC), chlortetracycline hydrochloride (CTC) and tetracycline hydrochloride (TC). In the rural 72 out of 229 (31.4\%) samples were positive after screening while none of the samples confirmed the presence of tetracyclines after analysis with HPLC-UV. Sulphonamides confirmed after analysis with HPLC-UV were all above the EU MRL limits. In the peri urban 28.8\% (23/80) of the samples were positive for antibiotic residues. Tetracyclines were not detected in confirmation while $60 \%$ of the positive samples were positive for sulphonamides out of which $71 \%$ were above the regulatory limits. Highest percentage of antibiotics was detected in rural farms (46.7\%) and at peri urban bulking centers (50\%).

Conclusion: The study concluded that antibiotic residues along the dairy value chain are majorly from the farm due to lack of withdrawal periods followed by intentional addition along the value chain. Value chain actors should also be trained on ways of avoiding antibiotic residues from entering the dairy value chain to protect the public from health effects related to antibiotic residues.
\end{abstract}

Keywords: Antibiotic residues, Contaminants, Tetracyclines, Sulphonamides, Dairy value chain, Rural, Peri-urban

\footnotetext{
*Correspondence: deborahorwa@gmail.com

${ }^{1}$ Department of Dairy Food Science Technology, Egerton University, Faculty

of Agriculture, P.O. Box, 536-20115, Egerton, Kenya

Full list of author information is available at the end of the article
} 


\section{Background}

Antibiotics are defined as the antimicrobial substances that are produced either naturally by living organisms or synthetically by laboratory procedures with the ability to inhibit the growth of microorganisms or kill the microorganisms (Wageh et al., 2013). Antibiotics are manufactured for the purpose of the prevention and treatment of animal diseases such as mastitis, arthritis, brucellosis, gastrointestinal diseases, respiratory diseases and many other bacterial infectious diseases (Tollefson and Miller 2000). In intensified farming antibiotics are also used to improve animal production like increase of growth rate and fattening (Nisha, 2008). When these antibiotics are administered to an animal, they dissolve and distribute rapidly in animal tissues and fluids. Over $90 \%$ of these antibiotics bind to plasmic proteins and reach a high concentration between the $3^{\text {rd }}$ and $6^{\text {th }}$ hour of administration (Sulejmani et al., 2012). They are then metabolized in the liver and are excreted through glomerular filtration. If the right procedure is not used in administration and use of these drugs they are left in large amounts i.e., residues, in animal products like milk and meat (Richelle, 2007). Once they are in the milk, there is a carry-over effect along the milk value chains.

The most common antibiotics used in animal husbandry include sulfonamides, tetracyclines, beta lactams, aminoglycosides, lincosamides, macrolides and pleuromutilins (Lee et al. 2001). The most common sulphonamides are sulfadiazine, sulphadimidine sulfamethoxazole, sulfamerazine, sulfadimethoxine, sulphasalazine, sulfisoxazole and silver sulfadiazine, which have the sulfonamide as the base structure (Chung et al., 2009). In countries like Kenya, the prevalence of tetracycline's was recorded to be highest at $55 \%$, followed by sulfonamides at $21 \%$ and beta lactams at 6\% (Mitema et al. 2001; Shitandi and Sternesjö 2004). According to Aboge et al. (2000), the most common antibiotics used in the treatment of livestock were beta lactams, sulfonamides, tetracyclines and aminoglycosides. Antibiotic residues in milk along the value chain have been reported to be above the maximum residual levels (MRL) in Kenya (Aboge et al., 2000; Shitandi and Sternesjö 2004). The main causes of antibiotics residues in milk have been attribute to by lack of observing withdrawal period, extra label usage of drugs, contamination of animal feed with feces of treated animals, or the use of unlicensed antibiotics (Nisha, 2008). Other studies have also attributed the occurrence antibiotics in animal products to lack of educational training in antibiotic use and their effects (Shitandi and Sternesjö 2004; Okeke et al. 1995).

According to the European union and Codex Alimentarious regulation for maximum residual limits, sulfonamides should not exceed $100 \mu \mathrm{g} / \mathrm{kg}$, while tetracyclines should not exceed $100 \mu \mathrm{g} / \mathrm{kg}$ (EUR-Lex 2010; Codex
2012). Antibiotics have been identified in other parts of the world falling above the standard residual limits, including Germany (Kress et al., 2007), Netherlands (Abjean et al. 2000), Mexico (Tolentino et al., 2005) Turkey (Alkan, 2007) among others. Other African countries have also been reported to have milk contaminated with Antibiotic residues. Some of these countries include Egypt, Ghana, Ethiopia, south Africa, Nigeria, Tanzania and Sudan (Myllyniemi et al. 2000; Kurwijila et al. 2006; Goudah et al. 2007; Addo et al., 2011; El-tayeb et al. 2012).

The most recent research on antibiotic residues has recorded higher levels in milk. In Kenya in autum of 2010, 2.5\% samples tested positive for sulphonamides while $0.6 \%$ were reported to contain tetracyclines (Ahlberg et al., 2016). High levels of tetracyclines were reported in Algerian milk and milk products in study by Layada et al. (2016). Chowdhury et al. (2015) reported levels of antibiotic residues above recommended levels in Bangladesh milk. Over $60 \%$ of milk samples tested positive for antibiotic in Nigerian milk and other milk products (Olatoye et al. 2016).

When milk and other animal products with high levels of antibiotic residues are ingested by humans, there is occurrence of numerous adverse health effects like permanent gene mutation and liver poisoning (Nisha, 2008). Sulfamethazine has been highly associated with including immunopathological effects, transfer of bacterial resistance to humans, hypersensitivity and carcinogenicity. Mutagenicity and nephropathy have been reported to be caused by gentamycin. Hepatoxicity, reproductive disorders and bone marrow toxicity have been related to the occurrence of some chlorophenical (Wageh et al., 2013). Penicillin however has been reported to be associated with allergy development. Tetracycline's are also capable of staining teeth in little children. Technologically, antibiotic residues in milk inhibit the growth of starter cultures used in the manufacturing of cultured milk products like yoghurt and cheese.

If no control measures are taken against the occurrence of antibiotic residues in animal products, its projected that there will be over $65 \%$ increase in antibiotic residue contamination worldwide in animal products between 2010 and 2030 (Van Boeckel et al. 2015). In Kenya reports on drug residues have increased gradually since 1978 where penicillin residues in milk was reported to be $1 \%$ (Kang'ethe et al., 2005), in 2000 there was $16 \%$ of drug residues reported (Omore et al., 2004; Kang'ethe et al., 2005) while Shitandi and Sternesjö (2004) reported 14.9\% of milk to contain penicillin. Further, in 2010 over $24 \%$ of milk at the farm level tested positive for antibiotic residues (Ahlberg et al., 2016). 
However, in the middle and low income countries, there is limited data on antibiotic usage and levels (Van Boeckel et al. 2015). Also, many studies on milk antibiotic residues in Kenya have majorly focused on tetracyclines and sulphonamide levels at the farm and market levels but no study has focused on the entire informal milk value chain. Therefore, the aim of this study was to assess the presence and levels of sulfonamides and tetracyclines contamination in raw milk from small scale farmers, transporters, and bulking centers who are key actors along the dairy value chain using rapid screening (Charm II Blue-Yellow) and confirmation by HPLC.

\section{Methodology}

\section{Study site}

The study was carried in Nakuru County which is rated as a high milk production center in the country. It is estimated to produce over 40 million liters of milk per annum (Ministry of Livestock Development Department and Fisheries 2012). The divisions within the county where the study was carried out were; Olenguruone, Bahati and Wanyororo. Olenguruone division represented a rural dairy system which lies at $35^{\circ} 40^{\prime} 60^{\prime \prime} \mathrm{E}$ and $0^{\circ} 34^{\prime} 60^{\prime \prime} \mathrm{S}$ DMS (degree minute seconds). Wanyororo and Bahati divisions represented the peri- urban locations at $36^{\circ} 16^{\prime} 12^{\prime \prime} \mathrm{E}$ and $0^{\circ} 12^{\prime} 0^{\prime \prime} \mathrm{S}$. Samples were collected between January 2014 and November 2015.

\section{Sampling}

A nested design (in RCBD) was applied in sample collection where the nodes were nested within the locations. Sampling was done in three visits to the dairy system. The first visit 40 samples were collected from the farm, 35 samples from transporters and the three bulking centers were sampled from. This provided a total of 79 samples per visit in the rural dairy system. In the peri urban dairy system, 17 farms were visited with one cow per farm being sampled from, 7 milk transporters were sampled and the two cooling centers in that diary system were also sampled from. This provided a total of 26 samples per visit. Dairy farming is not a priority source of income for the population in peri urban and hence less than fifty percent of the population carried out dairy farming, hence a relatively smaller sample size was collected from the peri urban dairy system. Sample volumes were $100 \mathrm{ml}$ per sampling point, the samples were then stored at temperatures not higher than $4{ }^{\circ} \mathrm{C}$ and were analyzed within 2 months of sampling.

\section{Antibiotic analysis}

\section{Screening}

Screening was done using the Charm II Blue-Yellow test. The charm test is done using a kit which is provided by the manufacturer (ALDRICH). The kit has 96 wells containing a media, pre-measured bacterial spores (Bacillus stearothermophilus var. calidolactis) and a $\mathrm{pH}$ indicator. The Charm II Blue Yellow (Serial number: BlueYellowII.01843CharmInc.) kit has 96wells. The Kit detects 29 antimicrobials including beta lactams, sulphonamides, tetacyclines and aminoglycosides at and above EU maximum residual limits (MRL). The test is based on the principle of growth inhibition of the bacterial spores by antibiotics. The starting color of the bacterial wells is blue. If the sample is positive, the bacteria will be inhibited and there will be no color change hence the blue color will be retained after the test is completed. If the sample is negative, then the bacterial spores will germinate producing acid which will change the $\mathrm{pH}$ of the media to yellow. Samples which are not clearly positive will have a yellow to bluish color.

Thawed milk samples at room temperature, were centrifuged and the supernatant (not fat) was used in screening. Fifty microliter of the skimmed milk was measures and transferred into a well. The procedure was repeated until all samples were transferred to individual wells in duplicate. A positive control containing Penicillin $\mathrm{G}(4 \mathrm{ppb})$ and a negative control were included before proceeding. Wells with added samples and the controls were then incubated at $64{ }^{\circ} \mathrm{C}$ in a humidified incubator for three hours. At the end of the three hours, the wells were removed and observed for color changes which were read using interpretation chart provided by the manufacturer (Charm Blue Yellow II test Manual).

Suspect positive samples were further heated to $80{ }^{\circ} \mathrm{C}$ for $10 \mathrm{~s}$ to eliminate the presence of other natural antibiotic inhibitors, lysozyme and lactoferrin (Kellnerová et al. 2015; Layada et al., 2016). The boiled samples would then be taken through the charm screening test. Samples that tested negative were eliminated but those which remained positive and caution samples were preceded to the HPLC for confirmation and quantification.

\section{Standards and reagents}

The standards used in examination were; Sulfachloropyradizine (Sigma-Adrich 46778), Sulfadiazine (Sigma-Adrich 35033), Sulfadimidine (Sigma-Adrich 46802), Sulfaquinoxaline (Sigma-Adrich 45662), Sulfamerazine (Sigma-Adrich 46826), Sulfathiazole (Sigma-Adrich 46902), Sulfamethoxazole (Sigma-Adrich 46850), Sulfadoxin (SigmaAdrich 46810), Sulfadimethoxin (Sigma-Adrich 46794), Oxytetracycline (Sigma-Adrich 46598), Doxycycline hyclate (Sigma-Adrich 33429), Chlortetracycline hydrochloride (Sigma-Adrich 26430), Tetracycline hydrochloride (Sigma-Adrich 87130).

Reagents were Acetonitrile (J.T. Baker 9017), Methanol (J.T. Baker 8402), Trichloroacetic acid (J.T. Baker 0344), Disodium hydrogen phosphate (J.T. Baker 0326), Citric acid (Acros 124912500), Sodium-EDTA (J.T. 
Baker 1073), Calcium Chloride (Merck 1.2378.0500), Sodium Cetate (J.T. Baker 0258), Ammonium acetate (J.T. Baker 0011). Mobile Phase A was prepared by mixing $\mathrm{Na}$ acetate $(0.075 \mathrm{M})$ and Calcium Chloride $(0.035 \mathrm{M})$ to Sodium EDTA $(0.025 \mathrm{M})$ and the $\mathrm{pH}$ adjusted to 7.0. Mobile Phase B was prepared by mixing $75 \%$ methanol to $25 \%$ Acetonitrite.

\section{Equipment}

The equipment used in the study was Shimadzu HPLCJapan. Equipped with a UV-vis detector, SID 20A, Column Oven-CTO-10ASVP, X-Terra ${ }^{\mathrm{R}}$ MS $\mathrm{C}_{18}(3.5 \mu \mathrm{m}$, $2.1 \times 150 \mathrm{~mm}$ column Waters made in Ireland), an XTerra Guard column C18 $(3.5 \mu \mathrm{m}, 2.1 \times 10 \mathrm{~mm})$ solvent delivery module, LC 20AT, degassing unit DGU-20A $\mathrm{A}_{3}$, an auto sampler SIL-20AHT and system controller CBM-20A connected to a HP intergrator with LC Solution Version 3.5 Shimadzu Corp-Japan.

\section{Confirmation}

Positive suspects were confirmed using HPLC where exact antibiotic quantities were determined. The following antibiotics were sought out based on the high prevalence of Mastitis in both locations. These antibiotics included; Sulfachloropyradizine (SCL), Sulfadiazine (SDZ), Sulfadimidine (SMTZ), Sulfaquinoxaline (SQ), Sulfamerazine (SMR), Sulfathiazole (STZ), Sulfamethoxazole (SMX), Sulfadoxin (SDOX), Sulfadimethoxin (SDM), Oxytetracycline (OTC), Doxycycline hyclate (DC), Chlortetracycline hydrochloride (CTC) and Tetracycline hydrochloride (TC). The antibiotics selected are also wide in spectrum in terms of their activity and are usually used in treating other bacterial diseases among cattle.

The HPLC procedure used had four main steps as described by Mamani and Reyes (2009) and Koesukwiwat et al. (2007). These were; (a) protein precipitation and purification by centrifugation and trichloroacetic acid and McIIvaine-EDTA buffer, (b) Sample extraction with Oasis HLB (200 mg) cartridge, (c) sample evaporation and (d) quantification by HPLC with gradient mode on $\mathrm{C}_{18}$ column and UV-detection.

\section{Sample preparation \\ Protein precipitation and purification}

$5 \mathrm{ml}$ of presumptive positive sample was measured into a $25 \mathrm{ml}$ centrifuge tube; $2.5 \mathrm{ml}$ of $25 \% \mathrm{TCA}$ in water was added and mixed for $10 \mathrm{~s}$ by vortexing. $10 \mathrm{ml}$ of Mcllavine- EDTA buffer was added to the mixture, vortexed (Vortex-Assistant- Reamix 2789) for $10 \mathrm{~s}$ and then mixed in a sonicator (Power Sonic405 LUC) for $10 \mathrm{~min}$. This mixture was then centrifuged at $400 \mathrm{rpm}$ at $10{ }^{\circ} \mathrm{C}$. The clear supernatant was poured out to a new $25 \mathrm{ml}$ centrifuge tube with the fat remaining in the tube walls.
To the old centrifuge tube containing the subnatant, $10 \mathrm{ml}$ Mcllavine-EDTA was added and mixed by vortexing for $10 \mathrm{~s}$. This was the sonicated for another $10 \mathrm{~min}$. This was then centrifuged (Centrifuge- HeraeusLabofuge) at $4000 \mathrm{rpm}$. The resulting supernatant was mixed with old supernatant initially collected from the same sample.

\section{Solid phase extraction}

The $\mathrm{C}_{18}$ cartridges (Oasis HLB cartridges C18, 6 cc $200 \mathrm{mg}$, waters Corporation USA) were marked and fixed on the solid extraction vacuum. Additional funnels (20 ml) were fixed on the cartridges. The C18 column cartridge was activated by $5 \mathrm{ml}$ methanol, followed by $10 \mathrm{ml}$ acetonitrile then $5 \mathrm{ml}$ Mcllavine-EDTA without letting the cartridge run dry. The clear supernatant was then poured to the cartridge funnels so that it trickles through in approximately $20 \mathrm{~min}$. This was then washed with $5 \mathrm{ml}$ methanol in Mcllavine. The cartridge was then dried by using the vacuum drier. After the vacuum was relieved the washes under the cartridge were discarded marked glass tube for sample collection was placed under the cartridges. $5 \mathrm{ml}$ of methanol was added to the dry cartridge and allowed to absorb for $5 \mathrm{~min}$ after which the samples were eluded out of the cartridge at a flow rate of $1 \mathrm{ml} / \mathrm{min}$.

\section{Evaporation}

Glass tubes containing methanol eluent were placed in a sand bath at $50{ }^{\circ} \mathrm{C}$ to evaporate the methanol and leaving a thick fluid at the bottom of the glass tube.

\section{HPLC analysis}

Sulphonamides were detected at $265 \mathrm{~nm}$ while Tetracyclines were detected at $385 \mathrm{~nm}$. The column temperature was set at $40{ }^{\circ} \mathrm{C}$ while the flow rate was at $0.2 \mathrm{ml} / \mathrm{min}$. Used gradient was A:B 90:10 at 0-35 min, 65:35 at 35-36 $\mathrm{min}, 90: 10$ at 36-45 $\mathrm{min}$ and 90:10 at 45-55 min. sample run time was $45 \mathrm{~min}$ while the injection volume was $10 \mu$ l. The retention times of Sulphonamides (SDZ, SMX, SMR, SCL, SDOX, SMTZ, SDM, SQ) was $4 \mathrm{~min}, 7 \mathrm{~min}, 7 \mathrm{~min}, 8 \mathrm{~min}, 8 \mathrm{~min}, 14 \mathrm{~min}, 16 \mathrm{~min}$ and $17 \mathrm{~min}$ respectively. The retention times for tetracyclines (OTC, DC, TC and CTC) were $11 \mathrm{~min}, 24 \mathrm{~min}$, $33 \mathrm{~min}$ and $36 \mathrm{~min}$ respectively.

The remaining fluid in the glass tube (from evaporation stage) was added to $200 \mu$ lof mobile phase. This was then mixed by vortexing for $15 \mathrm{~s}$. $0.3 \mu \mathrm{l}$ of mobile phase A was added to the mixture and vortexed vigorously for $15 \mathrm{~s}$. The sample was then filtered through $0.2 \mu \mathrm{m}$ syringe filter to HPLC vials and put inside the HPLC and results were generated after the run time was completed. 


\section{Calibration}

Calibration graphs were first determined by preparation of different concentration of the standard solutions. From a stock solution of $1 \mathrm{mg} / \mathrm{ml}$ of each standard the following concentrations were prepared; 2,000 $\mathrm{ng} / \mathrm{ml}$, $1,000 \mathrm{ng} / \mathrm{ml}, 500 \mathrm{ng} / \mathrm{ml}$ and $50 \mathrm{ng} / \mathrm{ml}$ using mobile phase A. The calibration graphs produced by the standards were used to determine the concentration of drugs in the samples. The calibration curves were used to provide information on recovery, retention factor and the standard deviation. The Limits of detection were also provided, but these were equipment and procedure specific and were provided by the manufacturer of the HPLC-UV. Results of calibration are as shown in Table 1. The standard calibration curves used in the generation of results were generated based on a formula by (Sulejmani et al. 2012). The absorbance read became a percentage (\%) of optical density relative to zero standards $\mathrm{B}_{0}$ and it is based on the calibration line assigned to each series of standard solutions and has the following formula:

$$
\mathrm{y}=\mathrm{a}+\mathrm{b} * \ln \mathrm{X}
$$

Y-read signal expressed in\% of optical density,

$\mathrm{X}$-concentration of the substance and $\mathrm{a}$ and $\mathrm{b}$ coefficients.

In every batch of samples analyzed for values of $\mathrm{Rr}^{2}$, tetracycline's must be at least 0.8278 , while the sulphonamides' $\mathrm{Rr}^{2}>0.98$. The calibration curve results are presented in Table 1.

The calibration curve provides information on recovery, retention factor and the standard deviation. The
Limits of detections are also provided in the table but these are equipment and procedure specific and were provided by the manufacturer of the HPLC-UV. One such calibration curve has been provided in Fig. 1. The figure shows calibrationn curves for SDM and SMTZ.

\section{Method validation}

The method was validated by the use of blank samples $(n=7)$ spiked with a concentration of $200 \mathrm{ng} / \mathrm{ml}$ of all the sulphonamides (SCL, SDZ, SMTZ, SQ, SMR, STZ, SMX, SDOX, SDM) and tetracycline's (OTC, DC, CTC, TC). The spiked and blank samples passed through sample preparation as other milk samples described above. In the validation procedure Sulfachloropyradizine (SCL) was not eluded in any of the7 spiked samples. However Sulfadiazine was only eluded from one of the spiked sample hence it was not possible to calculate a standard deviation as reported in Table 2.

\section{Results}

Out of 229 samples in the rural dairy system, 72 (31.4\%) samples tested positive after screening. Caution samples were treated as positive samples since all of them were preceded to confirmation stage by HPLC-UV. Out of the positive rural samples from charm test, 59 (56 confirmed positive and 3 caution samples) were from farm level, 12 samples at the transporters and 1 sample was from the bulking center. In the peri urban dairy system, out of the 80 samples collected 23 samples were positive including caution. Out of which 14 of them were recorded at the farm level, 4 at the transporters node and 2 samples at the bulking center. Samples which did not produce a distinct colour were treated as caution and were

Table 1 Calibration curves results of standards

\begin{tabular}{|c|c|c|c|c|c|}
\hline STANDARS & Regression equation from calibration curves & $\mathrm{Rr}^{2}$ & LOD HPLC-UV & RF & SD (\%) \\
\hline$\overline{S M R}$ & $f(x)=662.48 x+74645.3$ & 1.0 & 50 & 737.1 & 0.08 \\
\hline SDOX & $F(x)=376.583 x+1846.29$ & 1.0 & 100 & 378.4 & 0.004 \\
\hline SCL-rt30 & $F(x)=17.72 x-7393.03$ & 1.0 & 100 & 10.3 & 0.62 \\
\hline SDZ & $F(x)=340.51 x+2232.01$ & 1.0 & 50 & 342.7 & 0.005 \\
\hline SMTZ & $F(x)=321.58 x+4987.23$ & 1.0 & 50 & 326.6 & 0.013 \\
\hline SQ & $F(x)=259.997 x+1480.45$ & 1.0 & 50 & 258.5 & 0.005 \\
\hline SDM & $F(x)=292.90 x-8808.51$ & 1.0 & 80 & 284.1 & 0.027 \\
\hline SMX & $F(x)=386.15 x-297.48$ & 1.0 & 50 & 385.9 & 0.001 \\
\hline STZ-32 & $F(x)=65.84 x+18977$ & 1.0 & 50 & 84.8 & 0.19 \\
\hline OTC & $F(x)=43.30 x+48278.9$ & 1.0 & 40 & 91.6 & 0.46 \\
\hline DC & $F(x)=55.08 x+29908.4$ & 1.0 & 40 & 85 & 0.3 \\
\hline CTC & $F(x)=127.8 x+18909.9$ & 1.0 & 40 & 146.7 & 0.11 \\
\hline TC & $F(x)=63.85 x-2396.01$ & 1.0 & 40 & 61.5 & 0.034 \\
\hline
\end{tabular}

$\mathrm{Rr}^{2}$ recovery ratio, RF: retention factor, LOD:limit of detection, SD:standard deviation, Sulfachloropyradizine (SCL), Sulfadiazine (SDZ), Sulfadimidine (SMTZ), Sulfaquinoxaline (SQ), Sulfamerazine (SMR), Sulfathiazole (STZ), Sulfamethoxazole (SMX), Sulfadoxin (SDOX), Sulfadimethoxin (SDM), Oxytetracycline (OTC), Doxycycline hyclate (DC), Chlortetracycline hydrochloride (CTC) and Tetracycline hydrochloride (TC) 


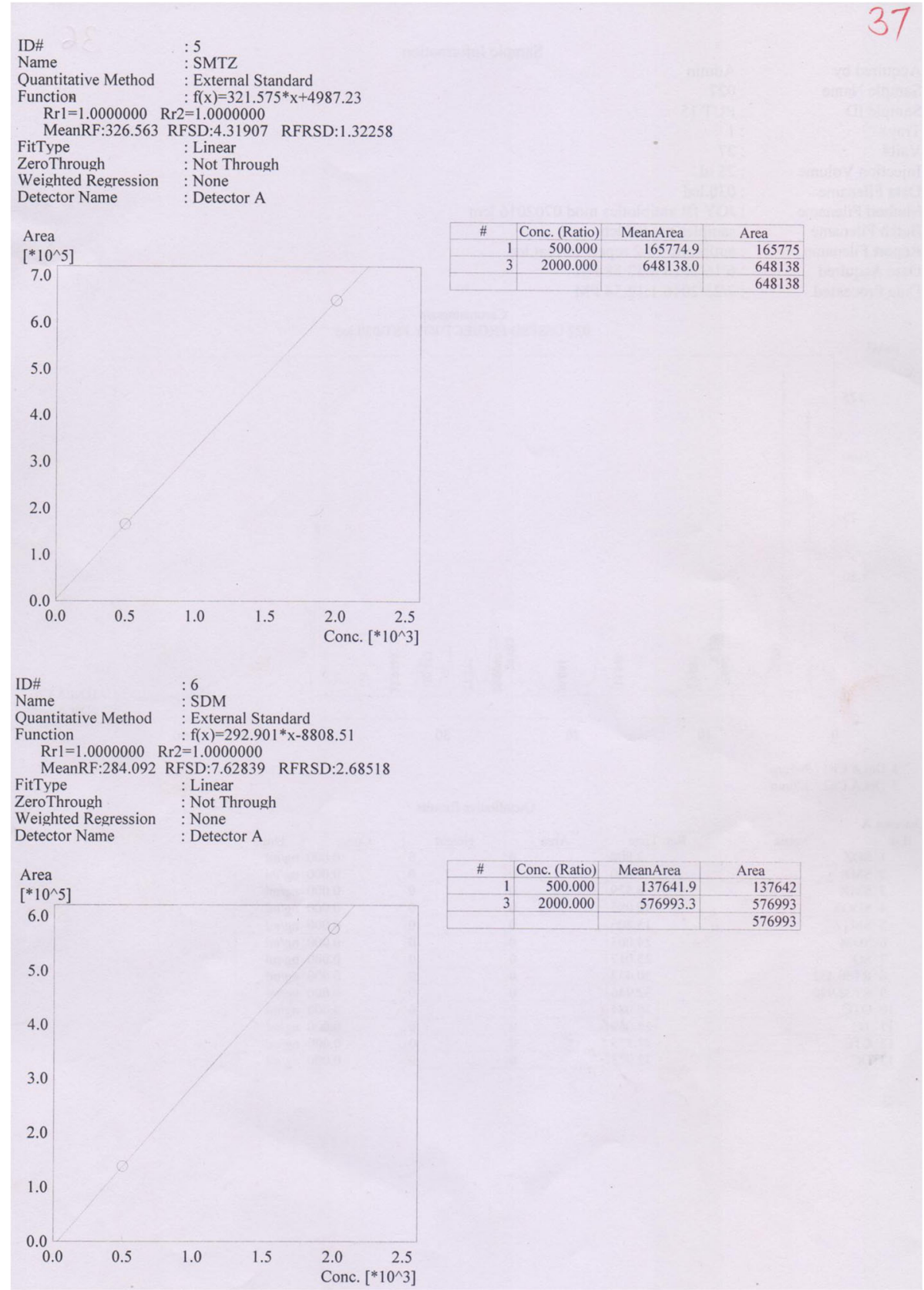

Fig. 1 Calibration curves for SMTZ and SDM

Table 2 Results from method validation using spiked milk samples

\begin{tabular}{|c|c|c|c|c|c|c|c|c|c|c|c|c|}
\hline Samples & SDZ & SMX & $\mathrm{SCL}$ & SMR & SDOX & SMTZ & SDM & SQ & OTC & DC & TC & CTC \\
\hline Recovery (mean \%) & 144 & 92 & - & 71 & 71 & 112 & 56 & 42 & 99 & 92 & 70 & 64 \\
\hline SD & - & 6.2 & - & 5.2 & 3.9 & 7.0 & 3.2 & 2.7 & 3.7 & 5.7 & 3.2 & 4.5 \\
\hline
\end{tabular}


recorded as shown in Table 3 and were proceeded to HPLC for identification.

Results from the HPLC showed that none of the samples contained any of the four tetracyclines tested (OT, CTC, DOC, TC). All of the samples that tested positive for sulphonamides at the rural dairy system had values above the EU MRL levels. Positive samples for sulphonamides at the farm node and transporters node also recorded values higher than the EU MRL levels. At the bulking (coolong) center in the peri urban dairy system, SDZ and SDM however recorded values less than $100 \mathrm{ug} / \mathrm{kg}$ in the positive sample. Only 2 samples recorded presence of sulphonamides in the rural farms, 1 sample at the transporters node and 1 sample at the bulking node recorded presence of sulphonamides. Samples positive for sulphonamides contained SDOX $(148.78 \mu \mathrm{g} / \mathrm{kg}$ )), SDZ $(90.03 \mu \mathrm{g} / \mathrm{kg})$, SDM $(66.14 \mu \mathrm{g} / \mathrm{kg})$ and SMX $(8,979.59 \mu \mathrm{g} / \mathrm{kg} ; 8,979.51 \mu \mathrm{g} / \mathrm{kg})$. A sample of a positive Chromatogram has been provided in Fig. 2 (for SDOX). Results for quantity of antibiotics are recorded in Table 4. The mean concentrations of the antibiotic contaminants were significantly different between locations. The highest mean concentration was recorded at peri urban bulking center which was highest for all the nodes (Fig. 3).

\section{Discussion}

After screening, no sample tested positive for any of the tetracyclines in the confirmation stage. Charm BlueYellow kit tests for the presence of a wide spectrum of antibiotics including betalactams, sulphonamides, tetracyclines and most of the antibiotics used in animal husbandry. The lack of detection of sulphonamides or tetracyclines in some of the samples would indicate the presence of other antibiotics as well in these samples. These results are almost similar with those obtained by Ahlberg et al. (2016) in study to analyze antibiotic residues in milk from smallholder farms in Kenya. The study used two methods to screen for presence of antibiotics, but the HPLC was not able to detect any antibiotic concentrations at and above the concentration used. The

Table 3 Screening results from Charm II Blue-Yellow Test

\begin{tabular}{llllll}
\hline Dairy system & Nodes & $N$ & Positive $(n)$ & Caution $(n)$ & Total \\
\hline Rural & Cows & 120 & $56(46.7 \%)$ & $3(2.5 \%)$ & \\
& Transporters & 105 & $11(9.5 \%)$ & $1(0.95 \%)$ & \\
\multirow{2}{*}{ Total } & Bulking & 4 & $1(25 \%)$ & 0 & \\
Peri urban & & 229 & 68 & 4 & $72(31.4 \%)$ \\
& Farm & 57 & $11(19.5 \%)$ & $3(5.3 \%)$ & \\
& Transporters & 21 & $6(28.6 \%)$ & $1(4.8 \%)$ & \\
Total & Bulking & 2 & $1(50 \%)$ & $1(50 \%)$ & \\
\hline
\end{tabular}

Charm II Blue Yellow kit eliminates the possibility of analyzing samples with inherent (natural antibiotics) through the second stage of screening. In this stage samples were exposed to heat treatment $\left(80{ }^{\circ} \mathrm{C} / 10 \mathrm{~min}\right)$ treatment to breakdown most natural inhibitors and also emulate high temperature short time pasteurization (Mullan, 2003; Kellnerová et al., 2014; Layada et al., 2016).

Presence of antibiotic residues in milk sampled at the farm from individual farms indicates that farmers are not observing withdrawal periods in lactating animals. A study done in Kosovo (Sulejmani et al. 2012), sulphonamide residue levels were compared based on time and delivery level. It showed that during the first days of delivery (1-4 days), sulphonamide levels remain high up to mid time after which the drug levels reduced significantly to incalculable levels towards the last days (day 5). This is an indication that since sulphonamides were detected in farm milk, the farmer milked the cow within 5 days of drug administration. Some farmers have attributed lack of observing withdrawal periods to harsh economic times (Shitandi and Sternesjö 2004). During treatment, the farmers however have to milk the cow to facilitate letdown but is expected to throw away the milk. Most farmers tend to find this practice difficult since the physical appearance of the milk is similar to that from a cow that is not undergoing any form of treatment. A part from lack of withdrawal, animal feed can be contaminated with antibiotics through feces or poor disposal of treatment kits containing antibiotics (Aboge et al., 2000; Kang'ethe et al., 2005).

The number of positive farm samples in the rural was slightly higher than positive samples in the peri urban dairy system. This shows that consumers in rural setting are more likely to consume milk contaminated with antibiotic residues than those in peri urban. This would be possible if these consumers buy milk directly from the farmers, which is a common practice in the rural area. These findings are similar to those of Aboge et al. (2000) and Kang'ethe et al. (2005) they reported that rural farmers are three times more likely to consume milk contaminated with antibiotic residues compared to their counterparts in the peri urban farms.

Antibiotic residues in transporters milk, shows that the antibiotics may have been intentionally added to milk to extend their shelf life. Transporters collect milk from farms and deliver them to the next value chain node. These include cooling centers which are collection points for dairy processing factories. Transporters face a challenge of milk spoilage since they transport the milk without any cooling facilities. Milk at this node is at a high risk of spoilage due to time taken moving from one farm to the other before reporting to the cooling center. Most transporters however, have been reported to add antibiotics to milk to prevent milk spoilage 


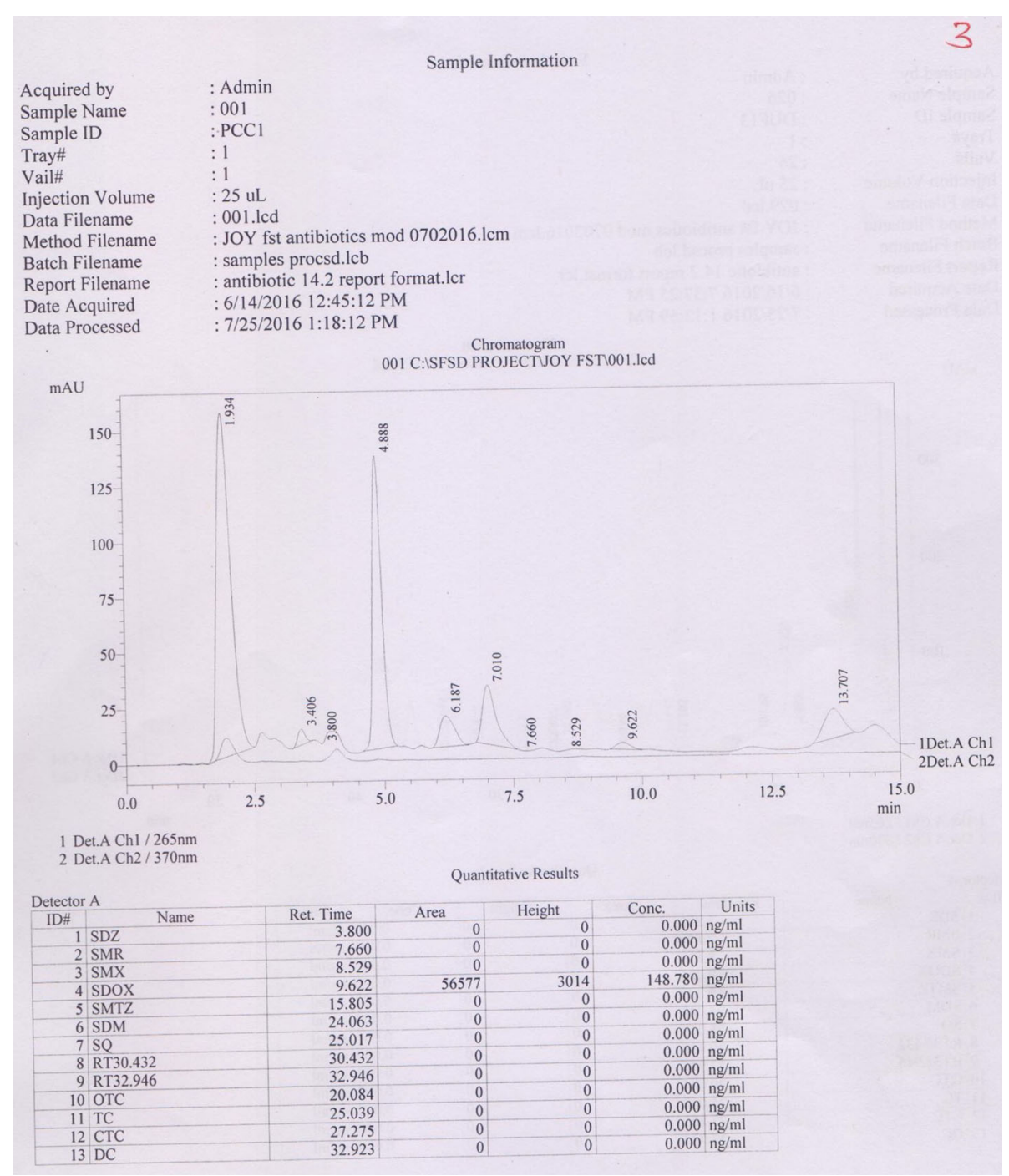

Fig. 2 A positive chromatogram for SDOX at a value chain node

(Aboge et al. 2000). Occurrence of antibiotic residues at the transporters node in peri urban is four times higher than in rural location. Consumers of dairy products and milk in the peri urban are more likely to consume milk with added antibiotics to extend shelf life. The prevalence of antibiotic contaminants was highest at rural farms (Table 3) while the concentration at this node was significantly lower than bulking centers in the peri urban (Fig. 3). This result indicates that the amount of antibiotic contaminants due to lack of observing withdrawal period, is lower than quantities added along the value chain.

The percentage positive samples from screening results in this study was $30 \%$, these results are slightly higher than those identified in the recent studies in Kenya. In 2004 Shitandi and Sternesjo recorded 14\%,
Ekuttan et al. (2007); 4\% Kang'ethe et al. (2005) 14\%. The proportion of sulphonamides groups in milk samples differs sparingly in this study compared to other studies done in Kenya. We found that sulphonamide occurred at $4.1 \%$ while tetracycline was at $0 \%$. A study by Ahlberg et al. (2016) recorded sulphonamides at $0.4 \%$ and tetracyclines at 2.5\%. Mitema et al. (2001) recorded sulphonamids at $24 \%$ and tetracyclines at $61 \%$.

Studies from different parts of Africa have reported different results from this study. In Tanzania over 36\% of milk supply chain was reported to contain antibiotic residues (Kurwijila et al. 2006). Other studies in Africa have also recorded the presence of antibiotic residues in milk like in Egypt (Goudah et al., 2007), Ghana (Addo et al. 2011), South Africa (Bester and Lombard 1979), Ethiopia (Myllyniemi et al. 2000), Sudan (El-tayeb et al. 
Table 4 Quantity of Sulphonamides and Tetracyclines

\begin{tabular}{llllllll}
\hline & \multicolumn{3}{l}{ RURAL (conc ppb) } & & & \multicolumn{2}{l}{ PERI (conc ppb) } \\
\cline { 2 - 3 } Residue & Farm & Transport & Bulking & & Farm & Transport & Bulking \\
\hline SMR & 0 & 0 & 0 & 0 & 0 & 0 \\
SDOX & 0 & 0 & 0 & 0 & 0 & 148.78 \\
SCL & 0 & 0 & 0 & 0 & 0 & 0 \\
STZ & 0 & 0 & 0 & 1923 & 0 & 0 \\
SMTZ & 389.176 & 0 & 0 & 0 & 0 & 0 \\
SQ & 0 & 0 & 0 & 0 & 0 & 0 \\
SDZ & 0 & 0 & 0 & 0 & 0 & 90.03 \\
SDM & 0 & 0 & 2305 & 0 & 674.83 & 66.14 \\
SMX & 179.026 & 2389.844 & 0 & 0 & 0 & 8979.59 \\
Positive & 2 & 1 & 1 & 1 & 1 & 2 \\
OTC & 0 & 0 & 0 & 0 & 0 & 0 \\
DC & 0 & 0 & 0 & 0 & 0 & 0 \\
CTC & 0 & 0 & 0 & 0 & 0 & 0 \\
TC & 0 & 0 & 0 & 0 & 0 & 0 \\
\hline
\end{tabular}

Sulfachloropyradizine (SCL), Sulfadiazine (SDZ), Sulfadimidine (SMTZ), Sulfaquinoxaline (SQ), Sulfamerazine (SMR), Sulfathiazole (STZ), Sulfamethoxazole (SMX), Sulfadoxin (SDOX), Sulfadimethoxin (SDM), Oxytetracycline (OTC), Doxycycline hyclate (DC), Chlortetracycline hydrochloride (CTC) and Tetracycline hydrochloride (TC)

2012) and Nigeria (Olufemi and Ehinmowo 2009) among others. In other nations of the world antibiotic residues has been reported in raw milk. In 2007 Kress and other coauthors reported $1.6 \%$ of samples to contain sulphonamides in Germany. These are slightly lower than sulphonamides identified in raw milk in Netherlands in 2000 by Abjean. Sulphonamides have also been reported in milk in Mexico 51.3\% (Tolentino et al. 2005), Turkey (Alkan, 2007) and Korea (Chung et al. 2009). In the most recent studies, tetracyclines, sulphonamides and other antibiotics have been recorded at levels above recommended limits in milk at different nodes of the value chain (Olatoye et al., 2016; Chowdhury et al., 2016; Layada et al., 2016).

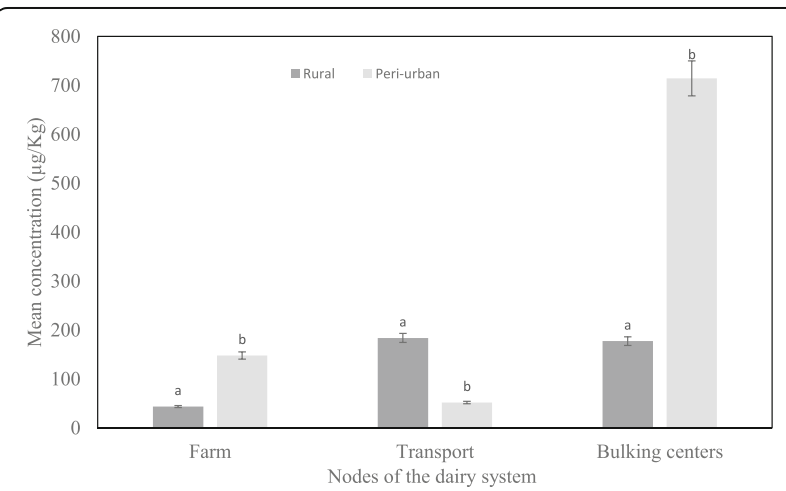

Fig. 3 Comparison of mean concentration of antibiotic residues in milk along the dairy value chains of rural and peri-urban systems
All sulphonamides detected read values above the EU MRL value except Sulfadiazine and Sulfadimethoxine which were below $100 \mu \mathrm{g} / \mathrm{kg}$ in this study. These levels also fall above the European Union Comission Regulation (EU) 2010 of antibiotic residues in raw milk. The rest of the samples were detected above the Limit of detection values of each antibiotic residue. This indicates that even higher levels than the read value might have been present. Sulfadiazine is a common antibiotic used in the veterinary practice in several countries and was recorded at the bulking center in the peri urban dairy system only.

The positive samples from Charm II Blue-Yellow test does not differentiate whether the result is due to antibiotic inhibitor or other growth inhibitors. Growth inhibitors used in the treatment of worm infections such as anthelmintics are possible sources of error for the Charm II Blue- Yellow Kit. According to this study, The Charm II Blue-Yellow was 97.1\% efficient in distinguishing between positive and negative samples since only 9 out of 309 samples were not clearly differentiated. These were labeled as caution samples and proceeded to HPLC UV for confirmation. None of the caution samples however, recorded the presence of sulphonamides or Tetracyclines under investigation. It is also likely that some sulphonamides were not detected due to presence of impurities in the sample. Sulphonamides are detected at a lower UV range of $268 \mathrm{~nm}$ where many impurities of biological origin can interfere with the analysis.

When milk is stored at ambient temperature, antibiotics degrade (Marth and Steele, 2001). When milk is slightly spoiled, the beta lactamse enzyme is produced and this would breakdown beta lactam antibiotics. The same is likely to occur to other antibiotics (Guay et al. 1987). In this study, samples were stored for a maximum of 2 months at $4{ }^{\circ} \mathrm{C}$ (frozen), however cold chain would not be maintained between storage and the point of analysis due to unavoidable circumstances. These challenges could explain the low levels of antibiotics detected by the HPLC-UV.

\section{Conclusion}

It can be concluded that presence of antibiotics in the farm is more common in the rural farms that the periurban farms. The level of antibiotics in the peri-urban increased through the transporters to the collection center. Lack of observation of withdrawal period might be a common practice given the high level of antibiotics in the farm milk. Addition of antibiotics for shelf life extension may be practiced more in the peri-urban by milk transporters. The study recommends the implementation of rapid tests along the value chain to be able to detect presence of antibiotics since this is not practiced in both locations. 


\section{Abbreviations}

CTC: Chlortetracycline hydrochloride; DC: Doxycycline hyclate; EU MRL: European Union Maximum Residual Limits; HPLC UV: High Performance Liquid Chromatography with Ultra Violet; LOD: Limit of detection; OTC: Oxytetracycline; RF: Retention; $\mathrm{Rr}^{2}$ : Recovery; SCL: Sulfachloropyradizine; SD: Standard deviation; SDM: Sulfadimethoxin; SDOX: Sulfadoxin; SDZ: Sulfadiazine; SMR: Sulfamerazine; SMTZ: Sulfadimidine; SMX: Sulfamethoxazole; SQ: Sulfaquinoxaline;

STZ: Sulfathiazole; TC: Tetracycline hydrochloride

\section{Acknowledgement}

We are grateful to the following individuals for their support in sample collection at the field, transportation to the laboratory Ms. Caroline Makau, Mrs. Faith Ndungi, Mr. Muyoma Nato, Mr. Olivier Kashongwe and Ms. Linnet Mwangi. Mr. Nderitu, and Mr. Pancras From Nairobi University are acknowledged for helping in sample analysis. Mr. Nobert Wafula is also acknowledged for data analysis and editing of this manuscript.

\section{Funding}

This research was funded by the Federal Government of Germany (BMBF) through ReLOAD (Reducing post harvest losses adding value in East African Food Value Chains) Project.

\section{Authors' contributions}

The authors JDO, JWM, PSM and PL participated in the design of the research and location of the study. JDO participated in data collection in the field, sample analysis, result generation and interpretation under close supervision of JWM, PSM and PL. PL was responsible in the analysis in availing the reagents and identification of the method and equipment for sample analysis by JDO. All authors read and approved the final manuscript.

\section{Authors' information}

Joy Deborah Orwa is a Masters Student with a Bachelors in Food Science and Technology from Egerton University. She has acquired skills in research including data analysis and interpretation especially in the Food Science. She also has experience working in the food industry. Joseph W. Matofari ia a Professor in Food Microbiology currently a senior lecturer at Egerton University in the Department of Dairy, Food Science and Technology. Patrick Muliro is a PhD holder in Dairy Science and a senior lecturer at Egerton University department of food science and technology. Peter Lamuka is a lecturer at Nairobi University in the department of Food Science, Nutrition and technology with vast knowledge in Food Safety. The three lecturers have supervised a number of Masters and PhD students over the years in their respective Universities.

\section{Competing interests}

The authors of this document have not declared any competing interests financial or non-financial in nature.

\section{Author details}

${ }^{1}$ Department of Dairy Food Science Technology, Egerton University, Faculty of Agriculture, P.O. Box, 536-20115, Egerton, Kenya. '2Department of Food Science, Nairobi University, Nutrition and Technology, P.O. Box 29053-00625, Nairobi, Kenya.

Received: 3 November 2016 Accepted: 14 February 2017

Published online: 28 February 2017

\section{References}

Abjean JP, Delepine B, Hurtaud-Pessel D. Qualitative or quantitative Methods for residue analysis? A Strategy for drug residue monitoring. Veldhoven: Proceedings of the Conference EuroResidue IV; 2000.

Aboge GO, Kang'ethe EK, Arimi SM, Omore AO, McDermot JJ, Kanja LW, Macharia JK, Nduhiu JK, Githua A. Antimicrobial Agents Detected in Marketed Milk in Kenya. Oral presentation at the 3rd All Africa Conference On Animal Agriculture. Smallholder Dairy Project. 2000

Addo KK, Mensah Gl, Aning KG, Nartey N, Nipah GK, Bonsu C, Akyeh ML, Smits $\mathrm{HL}$. Microbiological quality and antibiotic residues in informally marketed raw cow milk within the coastal savannah zone of Ghana. Trop Med Int Health. $2011 ; 16(2): 227-32$.
Ahlberg S, Korhonen H, Lindfors E, Kang'ethe E. Analysis of Antibiotic Residues in milk from Smallholder farms in Kenya. African J Dairy Farmin Milk Prodc. 2016;3(4):152-8.

Alkan A. The confirmation of used commercial kits in the detection of antibiotics in milk with HPLC (High Pressure Liquid Chromatography). Izmir: Master thesis. Graduate School of Engineering and Sciences of Izmir Institute of Technology; 2007.

Bester BH, Lombard SH. The effect of the dye-marking of mastitis remedies on the incidence of antibiotic residues in Pretoria's market milk supplies. J S Afr Vet Assoc. 1979;50(3):151-3.

Chowdhury S, Hassan M, Alam M, Sattar S, Bari MS, Saifuddin AK, Ahasanul MH. Antibiotic residues in milk and eggs of commercial and local farms at Chittagong, Bangladesh. Vet World. 2015;8(4):467-71.

Chung HH, Lee JB, Chung YH, Lee KG. Analysis of sulfonamide and quinolone antibiotic residues in Korean milk using microbial assays and high performance liquid chromatography. Food Chem. 2009;113(1):297-301.

Ekuttan CE, Kang'ethe EK, Kimani VN. Randolph TF Investigation on the prevalence of antimicrobial residues in milk obtained from urban smallholder dairy and non-dairy farming households in Dagoretti division, Nairobi, Kenya. East Afr Med J. 2007:84(11):87-91.

El-tayeb A, Barakat S, Marrone G, Shaddad S, Stålsby LC. Antibiotic use and resistance in animal farming: a quantitative and qualitative study on knowledge and practices among farmers in Khartoum, Sudan. Zoonoses Public Health. 2012;59(5):330-8.

European Union Commission Regulation (EU). On Pharmacologically active substances and their classification regarding Maximum Residual Limits in Food stuffs of animal Origin. 2010. EU 37/2010.

Goudah A, Sher S, Shin HC, Shim JH, Abd El-Aty AM. Pharmacokinetics and mammary residual depletion of erythromycin in healthy lactating ewes. J Vet Med A Physiol Pathol Clin Med. 2007:54(10):607-11.

Guay R, Cardinal P, Bourassa C, Brassard N. Decrease of penicillin G residue incidence in milk: A fact or an artefact? Int J Food Microbiol. 1987:4(3):187-96.

Kang'ethe EK, Aboge GO, Arimi SM, Kanja LW, Omore AO. McDermott JJ Investigation of the Risk of Consuming Marketed Milk with Antimicrobial Residues in Kenya. Food Control. 2005;16(4):349-55.

Kellnerová E, Navrátilová P, Borkovcová I. Effect of pasteurization on the residues of tetracyclines in milk. Acta Vet Brno. 2015;83(10):21-6.

Kress C, Seidler C, Kerp B, Schneider E, Usleber E. Experiences with an identification and quantification program for inhibitor-positive milk samples. Anal Chim Acta. 2007;586(1):275-9.

Koesukwiwat U, Jayanta S, Leepipatpiboon N. Solid-phase extraction for multiresidue determination of sulfonamides, tetracyclines, and pyrimethamine in Bovine's milk. J Chromatogr. 2007;1149(1):102-11.

Kurwijila LR, Omore A, Staal S, Mdoe NSY. Investigation of the Risk of Exposure to Antimicrobial Residues Present in Marketed milk in Tanzania. J Food Prot. 2006;69(10):2487-92.

Layada S, Benouareth D, Coucke E, Andjelkovic M. Assessment of antibiotic residues in commercial and farm milk collected in the region of Guelma (Algeria). Int J Food Contam. 2016:3:19.

Lee HJ, Lee MH, Ruy PD. Public health risks: Chemical and antibiotic residues. Asian Australas J Anim Sci. 2001:14(3):402-13.

Mamani MCV, Reyes FGR. Rath S Multiresidue determination of tetracyclines, sulfonamides and chloramphenicol in bovine milk using HPLC-DAD. Food Chem. 2009;117(3):545-52.

Marth EH, Steele JL. Applied Dairy Microbiology, vol. 2. New York: Marcel Dekker, Inc; 2001. p. 320-7.

Ministry of Livestock Development Department and Fisheries. MoLF District Livestock Production Annual Report. Nairobi: Nakuru North; 2012.

Mitema ES, Kikuvi GM, Wegener HC, Stohr K. An assessment of antimicrobial consumption in food producing animals in Kenya. J Vet Pharmacol Ther. 2001;24(6):385-90.

Mullan WMA. Inhibitors in milk. 2003. Available from: https://www.dairyscience.info/ index.php/inhibitors-in-milk/51-inhibitors-in-milk.html. Accessed 26 Jan 2017.

Myllyniemi AL, Rannikko R, Lindfors E, Niemi A, Bäckman C. Microbiological and chemical detection of incurred penicillin G, oxytetracycline, enrofloxacin and ciprofloxacin residues in bovine and porcine tissues. Food Addit Contam. 2000;17(12):991-1000.

Nisha AR. Antibiotics residues-A global health hazard. Vet World. 2008:1(12):375-7.

Okeke N, Lamikana A, Edelman R. Socioeconomic and behaviourial factors leading to acquired bacterial resistance in developing countries. Emerg Infect Dis. 1995;5(1):18-27. 
Olatoye IO, Daniel OF, Ishola SA. Screening of antibiotics and chemical analysis of penicillin residues in fresh milk and traditional dairy products in Oyo state, Nigeria. Vet World. 2016;9(9):948-54.

Olufemi Ol, Ehinmowo EA. Oxytetracycline Residues in Edible Tissues of Cattle Slaughtered in Akure, Nigeria. Internet J Food Safety. 2009;11(1):62-6.

Omore AO, Arimi SM, Kang'ethe EK, McDermott J. Analysis of Public Health Risks from Consumption of Informally Marketed Milk in Kenya. Kenya Vet. 2004;27(1):15-7.

Richelle RG. Investigation of Safe-Level Testing for Beta-lactam, Sulfonamide, and Tetracycline Residues in Commingled Bovine Milk. USA: Doctoral thesis, Salve Regina University; 2007.

Sulejmani Z, Shehi A, Hajrulai Z, Mata E. Abuse of Pharmaceutical Drugsantibiotics in Dairy Cattle in Kosovo and Detection of their Residues in Milk. J Ecosyst Ecogr. 2012;2(19):114-20.

Shitandi A, Sternesjö Å. Factors Contributing to the Occurrence of Antimicrobial Drug Residues in Kenyan Milk. J Food Prot. 2004:67(2):399-402.

Tolentino RG, Perez MA, Gonzales GD, León SV, López MG. Determination of the presence of 10 antimicrobial residues in Mexican pasteurized milk. Interciencia. 2005;30(5):291-4.

Tollefson L, Miller M. Antibiotic use in food animals: controlling the human health impact. J AOAC Int. 2000;83(2):245-54.

Van Boeckel TP, Charles B, Marius G, Bryan TG, Simon AL, Timothy PR, Aude T, Ramanan L. Global trends in antimicrobial use in food animals. Proc Natl Acad Sci. 2015;112(18):5649-54.

Wageh SD, Elsaid AE, Mohamed TE, Yoshinori I, Shouta N, Mayumi I. Antibiotic residues in Food: the African Scenario. Japanese J Vet Resear. 2013; 61(Supplement):13-22.

\section{Submit your manuscript to a SpringerOpen ${ }^{\circ}$ journal and benefit from:}

- Convenient online submission

- Rigorous peer review

- Immediate publication on acceptance

- Open access: articles freely available online

- High visibility within the field

- Retaining the copyright to your article

Submit your next manuscript at $\gg$ springeropen.com 